\section{Prolonged P-R interval in a male with 47,XYY karyotype}

SUMMARY A 47,XYY male with an extremely prolonged $\mathrm{P}-\mathrm{R}$ interval $(0.42 \mathrm{sec})$ on the electrocardiograph is described. There was also a secondary $R$ wave in lead $V_{1}$. He had no past history of heart disease and no cardiac abnormality on physical examination.

In 1968, Price reported a prolonged P-R interval in electrocardiograms of 47,XYY males. Later, he and his co-workers confirmed this finding in a larger sample (Price and Wilson, 1971; Price et al., 1974). However, several authors failed to support this finding (Noël et al., 1969; Steiness and Nielsen, 1970; Char and Borgaonkar, 1971; Borgaonkar, 1972). Thus, the length of the P-R interval in 47,XYY males remains controversial. We wish to report a $47, X Y Y$ male whose $\mathrm{P}-\mathrm{R}$ interval was extremely prolonged.

\section{Case report}

The case was one of five 47,XYY males identified in an incidence study among juvenile delinquents (Nanko et al., 1979). The parents were both 29 years old when he was born and were cousins. The patient, aged 18 years when identified, was the sixth in a sibship of six; he was a healthy man, $183 \mathrm{~cm}$ tall, and weighed $57 \mathrm{~kg}$. He had no past history or symptoms of heart disease. Physical examination including pulse, blood pressure, cardiac impulse, and heart sounds were all normal.

A conventional 12 lead electrocardiogram (leads I, II, III, aVR, aVL, aVF, V $_{1-6}$ ) was carried out. The $P-R$ interval was prolonged ( $P-R=0.42 \mathrm{sec})$. The normal range for Japanese adults is $0 \cdot 14$ to $0 \cdot 18 \mathrm{sec}$. There was a small secondary $R$ wave in lead $V_{1}$, but no notching or reduction in size of the $S$ wave in lead $V_{1}$. The electrocardiogram is shown in the Figure.

\section{Discussion}

Since the normal range of the P-R interval in

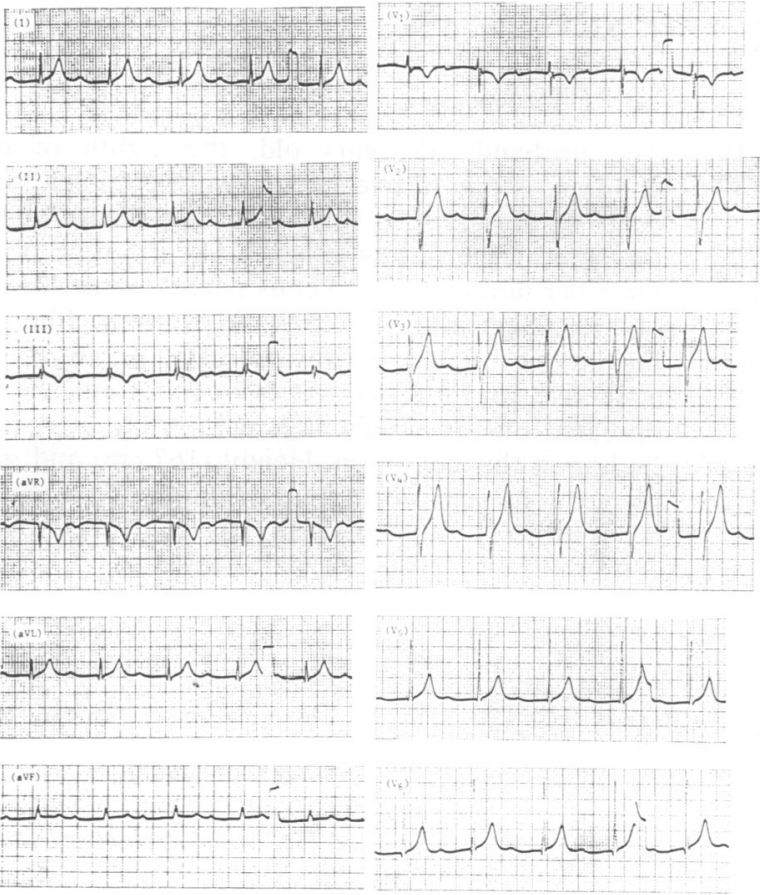

Fig. ECG record of case with $47, X Y Y$ karyotype. 
Japanese adults is 0.14 to $0.18 \mathrm{sec}, 0.42 \mathrm{sec}$ is thought to be exceedingly rare in this population. Price (1968) suggested that a prolongation of the P-R interval, secondary $R$ in lead $V_{1}$, and a reduction in size with notching of $S$ in $V_{1}$ were characteristic features of the electrocardiogram in 47,XYY males. The first two of these features were observed in the present case. There was no evidence of a cardiac abnormality to account for the electrocardiographic findings. More study is needed to clarify whether prolongation of the P-R interval in 47, XYY males is more than a coincidence.

Shinichiro NANKo ${ }^{1}$ AND JuNICHI MiYAWAKI ${ }^{2}$ Institute of Brain Research ${ }^{1}$ and Department of Gerontology, ${ }^{2}$ University of Tokyo, School of Medicine, Hongo 7-3-1, Bunkyoku, Tokyo, Japan

\section{References}

Borgaonkar, D. S. (1972). The XYY chromosome male or syndrome. In Progress in Medical Genetics, Vol. 10, ed A. G. Steinberg and A. G. Bearn. Grune and Stratton, New York. Cited by Borgaonkar and Shah (1974).

Char, F., and Borgaonkar, D. S. (1971). Electrocardiogram in males with the 47,XYY karyotype. Lancet, 1, 1242.

Nanko, S., Saito, S., and Makino, M. (1979). X and Y chromatin survey among 1581 Japanese juvenile delinquents. Japanese Journal of Human Genetics, 24, 21-25.

Noël, B., Quack, B., Durand, Y., and Rethoré, M. (1969). Les hommes 47,XYY. Annales de Génétique, 12, 223-236.

Price, W. H. (1968). The electrocardiogram in males with extra $Y$ chromosomes. Lancet, 1, 1106-1108.

Price, W. H., Lauder, I. L., and Wilson, J. (1974). The electrocardiogram and sex chromosome aneuploidy. Clinical Genetics, 6, 1-14.

Price, W. H., and Wilson, J. (1971). Electrocardiographic studies in individuals with different sex chromosome complement. Fourth International Congress of Human Genetics, 233, 531 (Abst.). Excerpta Medica, Amsterdam.

Steiness, E., and Nielsen, J. (1970). The electrocardiogram in males with the 47,XYY karyotype. Lancet, 1, 1402-1403.

Requests for reprints to Dr S. Nanko, Institute of Brain Research, University of Tokyo, School of Medicine, Hongo 7-3-1, Bunkyoku, Tokyo, Japan.
A case of complete testicular feminisation and 47,XXY karyotype

SUMMARY A very rare case of complet testicular feminisation with a $47, \mathrm{XXY}$ se chromosome complement is described. The chromatin is positive. The subject studied, who belongs to a family in which four other members have Morris's syndrome and have a 46,XY karyotype, is a perfect phenotypic female. The $\overrightarrow{\mathrm{s}}$ endocrine situation is unique and resembles, i part, that of subjects with Klinefelter's syndrom产

While there are many published reports on completio testicular feminisation with a $46, \mathrm{XY}$ karyotype, it is rare to find the same condition with a 47, XXYo complement. The report of German and Vesell (1966) describes Morris's syndrome and a 47,XXY karyotype in monozygotic twins, and Bartsch-Sandho et al. (1976) reported a case of incomplete testicula feminisation with the same chromosome complemen Subjects with the same syndrome and mosaicism od the sex chromosomes are very rare (Uozumi et al $\overrightarrow{\vec{r}}$ 1967; Gordon et al., 1969). We report the clinifat endocrine, and cytogenetic findings of a subject a rare coexistence of Morris's syndrome ans్ 47,XXY karyotype.

\section{Case report}

The proband, 35 years old, the eighth of nine children, is one of five subjects with complete testio cular feminisation in two successive generations of the same large family (Fig. 1). At the time of he birth her non-consanguineous parents were 40 years old (mother) and 48 years old (father). She is phenotypic female with primary amenorrhoea. attractive, and married. At 14 years of age she was operated on for a right inguinal hernia, a frequent finding in this condition. Height $(167 \mathrm{~cm})$ and bodys proportions are normal and similar to those in other subjects with Morris's syndrome. Facial, pubic

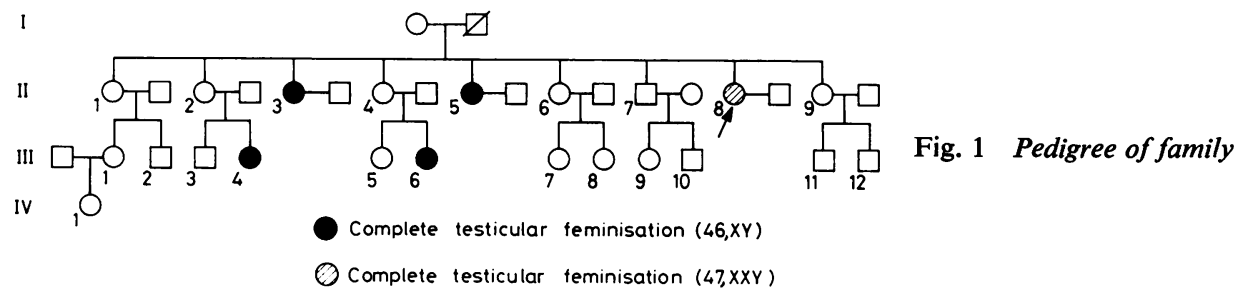

